\title{
Lumbar Disc Herniation
}

\author{
Raj M. Amin ${ }^{1}$ - Nicholas S. Andrade ${ }^{2}$ Brian J. Neuman ${ }^{1,3}$
}

Published online: 4 October 2017

(C) Springer Science+Business Media, LLC 2017

\begin{abstract}
Purpose of Review Substantial advancements have been made in the cause, diagnosis, imaging, and treatment options available for patients with lumbar disc herniation (LDH). We examined the current evidence and highlight the concepts on the frontline of discovery in LDH.

Recent Findings There are a myriad of novel etiologies of LDH detailed in recent literature including inflammatory factors and infectious microbes. In the clinical setting, recent data focuses on improvements in computer tomography as a diagnostic tool and non-traditional injection options including tumor necrosis alpha inhibitors and platelet-rich plasma. Operative treatment outcomes have focused on minimally invasive endoscopic approaches and demonstrated robust 5-year post-operative outcomes.

Summary Advances in the molecular etiology of LDH will continue to drive novel treatment options. The role of endoscopic treatment for LDH will continue to evolve. Further research into10-year outcomes will be necessary as this surgical approach continues to gain widespread popularity.
\end{abstract}

Keywords Lumbar disc herniation - Diagnosis of lumbar disc herniation $\cdot$ Non-operative treatment of lumbar disc

This article is part of the Topical Collection on Treatment of Lumbar Degenerative Pathology

Brian J. Neuman

bneuman7@jhmi.edu

1 Department of Orthopaedic Surgery, Johns Hopkins Hospital, Baltimore, MD, USA

2 Johns Hopkins University School of Medicine, Baltimore, MD, USA

3 Johns Hopkins Orthopaedic and Spine Surgery, 601 N. Caroline Street \#5241, Baltimore, MD 21287, USA herniation - Operative treatment of lumbar disc herniation · Minimally invasive discectomy $\cdot$ Endoscopic discectomy

\section{Introduction}

Nearly $80 \%$ of the population sustains an episode of low back pain (LBP) once during their lifetime [1]. Due to its high prevalence and significant contribution to disability, LBP incurs an annual cost exceeding $\$ 100$ billion in the USA $[1,2]$. Within the vast differential of LBP, the most common source is intervertebral degeneration leading to degenerative disc disease and lumbar disc herniation (LDH) [2]. Thus, an effective understanding of $\mathrm{LDH}$, its origins, and how to appropriately treat $\mathrm{LDH}$ is of substantial importance.

\section{Pathology of LDH}

The intervertebral disc consists of an inner nucleus pulposus (NP) and an outer annulus fibrosus (AF). The central NP is a site of collagen secretion and contains numerous proteoglycans (PG), which facilitate water retention, creating hydrostatic pressure to resist axial compression of the spine [3, 4]. The $\mathrm{NP}$ is primarily composed of type II collagen, which accounts for $20 \%$ of its overall dry weight. In contrast, the AF functions to maintain the NP within the center of the disc with low amount of PG; $70 \%$ of its dry weight is comprised of primarily concentric type I collagen fibers [3, 5, 6]. In LDH, narrowing of the space available for the thecal sac can be due to protrusion of disc through an intact AF, extrusion of the NP through the $\mathrm{AF}$ though still maintaining continuity with the disc space, or complete loss of continuity with the disc space and sequestration of a free fragment.

Several changes in the biology of the intervertebral disc are thought to contribute to LDH. These include reduced 
water retention in the NP $[5,7,8]$, increased percent of type I collagen within the NP and inner AF [9], degradation of collagen and extracellular matrix (ECM) materials [10], and upregulation of systems of degradation such as apoptosis, matrix metalloproteinase (MMP) expression, and inflammatory pathways [11].

\section{Genetic Predisposition}

A myriad of genes are involved in separate processes which predispose to LDH. It is estimated that the condition has approximately $75 \%$ heredity origin [12]. Genes that have been found to significantly increase risk of LDH include those encoding structural proteins, matrix metalloproteinases, apoptosis factors, growth factors, and single nucleotide polymorphisms in the vitamin D receptor gene resulting in inflammatory cytokine imbalance [11].

\section{Dehydration}

Dehydration is known to contribute to the pathogenesis of degenerative disc disease [7, 8]. Although a specific genetic polymorphism has not been associated with $\mathrm{LDH}$, aquaporins have been implicated. A recent study examined the removed discs of 18 patients who underwent surgery for L4-5 or L5-S1 herniation, and found aquaporin-I (AQPI) to be linearly correlated with preoperative $\mathrm{T} 2$-weighted magnetic resonance imaging (MRI) signal intensity [13•]. This suggests that AQPI may have a role in this dehydration, which is known to contribute to degeneration. However, more research is necessary to better elucidate the role of aquaporins in the pathogenesis of LDH.

\section{Axial Overloading}

Not all disc herniation occurs in the context of degenerative disease. A subset of patients with LDH lack evidence of severe degenerative disc including proteoglycan and water loss in the NP [14]. In these cases, herniation occurs as a result of spinal overloading $[15,16]$. A recent study of caprine intervertebral discs found that static overloading in particular, as compared to physiological loading and dynamic overloading, put the disc at risk for posterior herniation [17•]. The authors suggest that this may be the mechanism for the increased prevalence of lower back pain and herniation in younger individuals that live a sedentary and seated lifestyle.

\section{Etiology of Symptoms}

Several processes have been investigated in an attempt to understand how LDH produces its symptoms. These include inflammatory signaling, the presence and effects of
Propionibacterium acnes, contributions of an acidic environment, and microstructural changes to the nerve root.

\section{Inflammation}

The role of inflammatory signaling in producing nerve pain in LDH has been well-established. The intervertebral disc is an immunoprivileged area. Consequently, the contents of the intervertebral disc, specifically the NP, are immunoreactive if they are found beyond their normal physiological boundaries. As the NP tissue extrudes into the epidural space, vascular endothelial cell changes trigger increased vascular permeability, vasodilation, the adhesion and migration of immune cells to the site, and inflammatory cytokine signaling [18]. Moreover, several inflammatory factors including COX-2, its upregulator follistatin-like protein 1 (FSTL1), and tumor necrosis factor alpha (TNF- $\alpha$ ) have been shown to have significantly higher local and systemic concentrations in patients with LDH compared to non-herniated controls [19-22, 23•].

\section{Propionibacterium acnes}

Propionibacterium acnes is a Gram-positive, facultative anaerobic, fastidious bacterium, which may play a central role in LDH [24•]. In 2001, one study demonstrated that 53\% patients with severe radiculopathy were found to have Grampositive anaerobes. Nearly $84 \%$ of these patients were found to have $P$. acnes [25]. Recently, a significant portion of herniated discs $(11 \%)$ have been shown to have a high P. acnes bacterial load (> $1000 \mathrm{CFU} / \mathrm{mL}$ ) [26]. Aghazadeh et al. also found a high prevalence of $P$. acnes DNA and correlated it to vertebral edema as seen on preoperative MRI [27]. Chen et al. found that the bacterium was able to induce disc degeneration outright in rabbit models [28]. Furthermore, long-term antibiotics targeting anaerobes may improve lower back pain in those with disc herniation and vertebral edema [22]. Despite this, however, other studies have failed to correlate $P$. acnes prevalence with LDH pathology [29]. While it is likely that $P$. acnes may play a role in LDH symptomology and ultimately be a target for non-operative treatment, further research must be done to elucidate the measure of effect this bacteria has on symptomatic LDH.

\section{Acidic Environment}

Degenerated lumbar discs have a decreased $\mathrm{pH}(\sim 1.0)$ compared to that of healthy intervertebral discs, which is likely due to decrease metabolite exchange [30]. The consequence of this acidity has been increased expression of multiple factors which inhibit cell proliferation and increase cell apoptosis of NP cells $[31 \cdot, 32]$. Recent data in has shown that these changes are blunted in a dose-dependent manner with the 
administration of ASIC blockers, and that in non-human models, ASIC blockade improved pain threshold [31•].

\section{Clinical Presentation}

\section{Signs and Symptoms}

The primary signs and symptoms of LDH are radicular pain, sensory abnormalities, and weakness in the distribution of one or more lumbosacral nerve roots [33, 34]. Focal paresis, restricted trunk flexion, and increases in leg pain with straining, coughing, and sneezing are also indicative [33, 34]. Patients frequently report increased pain when sitting, which is known to increase disc pressure by nearly $40 \%$ [35].

The affect dermatome varies based on level of herniation as well as herniation type. In paracentral herniations, the transversing nerve root is affected versus in far lateral herniations, the exiting nerve root is affected. For example, a paracentral herniation at L4-5 would cause L5 radiculopathy whereas a far lateral herniation at the same level would cause L4 radiculopathy.

Pain that is relieved with sitting for forward flexion are more consistent with lumbar spinal stenosis (LSS), as the latter motion increases disc pressure by $100-400 \%$ and would likely increase pain in isolated LDH [35]. Rainville et al. recently compared signs of LDH with LSS and found that LSS patients are more likely to have increased medical comorbidities, lower levels of disability and leg pain, abnormal Achilles reflexes, and pain primarily in the posterior knee [36].

\section{Diagnostic Guidelines}

In 2014, The LDH with Radiculopathy Work Group of the North American Spine Society's (NASS) Evidence-Based Guideline Development Committee recommended manual muscle testing, sensory testing, and supine SLR test (and its crossed leg variant) as the gold standard for clinical diagnosis of LDH. Other tests such as the cough impulse test, hyperextension test, femoral nerve stretch test, lumbar range of motion, and absence of reflexes were not found to be as clinically helpful. A recent meta-analysis concluded that initial screening by the SLR test in conjunction with three of the following four symptoms in a nerve root distribution is sufficient for clinical diagnosis of LDH with radiculopathy: dermatomal pain, sensory deficits, reflex deficits, and/or motor weakness [37].

\section{Factors for Increased Risk of Cauda Equina Syndrome}

Cauda equina syndrome (CES) is a rare but devastating consequence of LDH. Krishnan et al. identified diabetes, acute onset of symptoms, L3-L4 involvement, sequestrated discs (fully separated NP from AF), superiorly migrated discs, posterior herniation, primary canal stenosis, and greater canal compromise as risk factors for CES [38•]. The presence of $\geq 4$ of these factors produced a significantly higher chance of CES (sensitivity $74 \%$, specificity $77 \%$ ).

\section{Imaging}

\section{Radiographs}

Plain radiographs are the first-line imaging modality used in low back pain. For the treating primary care physician, radiographs should be obtained only after 6-12 weeks in the absence of neurologic compromise. Given that radiographs provide only a static understanding of the spine, we recommend that in addition to anteroposterior (AP) and lateral images, flexion and extension sequences are obtained to evaluate the role of instability in the patient's symptoms. Findings suggestive of LDH in this modality include compensatory scoliosis, narrowed intervertebral space, and the presence of traction osteophytes.

\section{Magnetic Resonance Imaging}

Magnetic resonance imaging (MRI) is the gold standard for imaging to confirm suspected LDH with a diagnostic accuracy of $97 \%$ and high inter-observer reliability [39, 40]. MRI findings of increased $\mathrm{T} 2$-weighted signal from the posterior $10 \%$ of the disc diameter are highly suggestive of disc herniation [41]. However, given the significant resource use involved in this testing method, it is not indicated for all patients with LDH. Relative indications for MRI in the early period of LDH ( $<6$ weeks) include neurologic motor deficits and CES.

Diffusion tensor imaging (DTI) is a type of MRI that can be used to detect microstructural changes in the nerve roots in patients with LDH. Wu et al. assessed these changes and correlated them to disability score on the Oswestry Disability Index (ODI) and duration of sciatica symptoms [42]. Two microstructural parameters, low fractional anisotropy (more restricted osmosis in the tissue) and high apparent diffusion coefficient (decreased microstructural integrity of the nerve root), were associated with ODI score and symptom duration. This suggests that DTI may be able to be used to better understand the changes that occur in nerve roots due to compression in LDH, and differentiate patients between surgical and nonsurgical intervention.

\section{Modic Changes}

Modic changes are MRI signal changes representing categorized pathological changes occurring in vertebrae [43]. Modic type 1 changes are vascular developments in the vertebral body including inflammation and edema. Type 2 changes involve fatty replacement of the vertebral bone marrow. Type 3 
changes, which are less common, are fractures or changes of the trabecular bone of the vertebrae. Modic type 1 changes have been shown to correlate significantly with the degree of degenerative disk disease [44].

\section{Computed Tomography}

While computed tomography (CT) was previously thought to be clinically inferior to MRI in LDH detection, advances including multidetector $\mathrm{CT}$ (MDCT) have brought the diagnostic level of CT to be nearly equal to that of MRI $[45,46]$. The NASS Evidence-Based Guideline Development Committee recommends CT myelography as an appropriate diagnostic tool for confirming suspected LDH as an alternative to MRI [39]. There are several circumstances where CT myelography would be chosen as opposed to MRI including situations where MRI is unavailable or not possible (i.e., pacemakers or cochlear implants), and where patients would be excessively uncomfortable (claustrophobia or intractable back pain). However, given the invasive nature of this test, CT myelogram requires the assistance of a trained radiologist and is associated with risks including post-spinal headache (most common), radiation exposure, and meningeal infection.

\section{Treatment}

\section{Non-operative}

Non-operative management of symptomatic LDH is the treatment of choice for the majority of patients. Gugliotta et al. recently demonstrated equivalent medium- and long-term outcomes for conservative and surgical treatment of LDH [47]. However, other studies have also demonstrated improved 1and 2-year outcomes in the surgical treated group when compared to conservatively managed patients. There has been no recent literature which clarifies the absolute non-operative versus operative criteria in LDH. Relative indications for acute surgery are discussed in the next section. Nonoperative management should consist of a multimodal approach including anti-inflammatory medications, education, and physical therapy [48].

Local corticosteroid injections (CSI) are a commonly used technique for both the diagnosis and treatment of LDH. However, while interlaminar injection in acute LDH has shown a strong QALY benefit of $\$ 2050$, the optimal patient profile for maximum benefit remains unknown [49॰]. Historical success rates of these injections in acute LDH are 20-95\% [50] and are thought to be due to reduction in local inflammatory cytokine concentration. When compared to placebo injections, historical data suggests CSI offer short-term improvements in leg pain and sensory deficits but may not reduce the rate of surgical intervention or provide substantial functional benefit [51].
Prior data has shown that transforaminal injections produce superior results compared to caudal or interlaminar approach [52]. In an effort to enhance the success of this treatment, recent literature has examined the role of patient position during epidural CSI injection. Altun et al. found that injection in the lateral decubitus position provided statistically more 6-month ODI improvement and 12-month numeric rating scale improvement compared to prone positioning [53•].

Kim et al. evaluated radiologic factors predicting successful outcomes in nerve injections [54]. Their study demonstrated that LDH smaller than $6.23 \mathrm{~mm}$ demonstrated significant clinical improvement with transforaminal epidural steroid injection. However, their study also found that LDH greater than $6.31 \mathrm{~mm}$ demonstrated significant surgical benefit. Thus, measurement of disc herniation size may be of statistical, but minimal clinical, significance in determining likelihood of injection efficacy.

In addition to patient position, optimum injection medication is still under debate. As aforementioned, TNF- $\alpha$ is a critical molecular mediator in the pathogenesis of radiculopathy. However, the results of TNF- $\alpha$ blockade as a clinical treatment modality have been mixed thus far [55]. Korhonen et al. found the TNF- $\alpha$ inhibitor infliximab to be effective in treating sciatica in patients with LDH [56]. More recent data has shown that subcutaneous injection and epidural administration of TNF alpha inhibitors have shown clinical benefit, while intradiscal injection has shown no benefit at low dose [57]. In a placebocontrolled randomized trial of transforaminal TNF- $\alpha$ inhibitor injection, Freeman et al. demonstrated a significant 3- to 6month improvement in both worst leg pain and worst back pain scores with etanercept injections [55]. However, there was no dose-dependent response associated with this injection and no comparison population to CSI injection.

Much debate surrounds the use of non-traditional treatment modalities in the treatment of LDH. The combined effect of multi-modal non-traditional therapies including herbal supplementation, acupuncture, bee-venom pharmacopuncture, and spinal manipulation was investigated recently by Shin et al. [58]. Their study found that the long-term, 5-year, outcomes of this treatment method demonstrated broad improvements in VAS, ODI, and SF-36 QOL scores [58]. However, nearly 54\% had a relapse of either low back or radicular pain necessitating intervention including repeated non-operative therapy, injections, or surgery. Additionally, placebo effect cannot be excluded due to lack of a control population and recent data demonstrating a 66\% spontaneous resorption rate in LDH [59].

Another study evaluated the effect of traction therapy on short-term outcomes [60]. Both groups of patients using traction demonstrated improvement in 28-day outcomes, though there was no traction weight-dependent increase in improvement. The group allocated to traction equivalent to $10 \%$ of their body weight demonstrated better overall 28-day VAS scores compared to the $50 \%$ body weight group [60]. There 
was statistical decrease in opiate consumption in all groups and a reduction in the EIFEL disability scores for the $10 \%$ traction group. However, this study was limited by a small sample size of 17 patients and maximum of 2-week patient follow-up.

Traditional western formal physical therapy (PT) focused on exercise, core strengthening, and joint mobility are known to improve symptoms related to LDH [61]. Using the SPORT trial data, Thackeray et al. evaluated the profile of patients utilizing formal PT and their outcomes [62]. On multivariate analysis, those patients receiving early formal PT were more likely to have higher baseline ODI scores, prefer nonoperative treatment, and have an associated neurological deficit [62]. Within the first 6 weeks, there was no difference in the outcomes between the two groups. There was less 1-year low back pain in the formal physical therapy group, but no difference in pain, ability, or cross-over to surgery at 1 year compared to the non-formal PT group. Given the current national opioid epidemic, perhaps the most important finding was significantly less opiate usage in the formal PT group, though they had higher use of muscle relaxants compared to the non-formal PT group.

The regenerative effects of mesenchymal stem cell (MSC) therapy and wound healing benefits of platelet-rich plasma (PRP) injection for LDH are increasingly reported [63, 64]. Several studies have demonstrated improvement in clinical scores including ODI, VAS, and JOA beginning 1 month post-PRP injection [64-67]. Additionally, these studies have reported no complications associated with MSC and PRP injections [64]. However, the number of patients with outcomes reported in the literature is still too low for widespread clinical implementation.

\section{Operative}

Operative management of LDH in several large studies has been previously associated with improved short-term benefits and conflicting value in the medium- to long-term range [68, 69]. This finding was echoed by a recent randomized Finnish study comparing non-operative treatment with microdiscectomy in LDH [70]. Their study found no difference in 2-year measurements such as ODI score HRQoL between the two groups, but did demonstrate significant improvement in leg pain at 6 weeks, and patient reported treatment satisfaction at 2 years. Additionally, the most novel finding of this study was a subgroup analysis, which demonstrated that microdiscectomy of L4-5 LDH resulted in superior patient reported outcomes compared to non-operative management including subjective work ability, ODI, and HRQOL scores [70]. From a financial perspective, a recent Swiss study demonstrated that the incremental cost per quality-adjusted-life-year with surgical treatment was approximately $\$ 73,245$ [71].

Factors recently predicting successful outcome after discectomy include preoperative higher leg pain severity, better mental health status, shorter symptom duration, younger age, increased preoperative physical activity, and severe preoperative low back pain $[72 \bullet, 73,74]$. Interestingly, the presence of motor deficit, vertebral level or side of herniation, gender, and type I modic changes were not found to affect postoperative outcomes.

\section{Minimally Invasive Surgery}

Minimally invasive approaches to spine surgery have been pioneered and increasingly utilized over the last 15 years. These approaches are associated with less soft tissue and bony trauma, lower acute care charges, decreased hospital length of stay, but also with a higher learning curve $[75,76]$. As such, the outcomes of these procedures are increasingly reported.

There are several recognized percutaneous endoscopic approaches to LDHs: interlaminar, transforaminal, posterolateral, and transiliac $[77,78]$. As an aggregate group, endoscopic discectomy is associated with decreased operative time and less blood loss with no increase in overall complications, reoperation rates, or wound infection when compared to open discectomy [79]. However, with respect to long-term patientcentered outcomes, a double-blind randomized control trial failed to detect a difference between open and endoscopic surgery in 325 patients [80].

Choi et al. evaluated the outcomes of 149 patients undergoing percutaneous endoscopic lumbar discectomy (PELD) for migrated disc herniations [81]. They found a 90\% good or excellent outcome rate and improvement of 45 ODI points at 1-year follow-up. However, high-grade disc herniations with upward migration demonstrated a $13 \%$ rate of remnant disc fragment and $3 \%$ revision surgery rate.

Given the difficulty in utilizing the endoscopic approach with high iliac crests, Bai et al. applied a transiliac approach to endoscopic discectomy [77]. In comparison to the conventional transforaminal approach, there was no difference in 12month outcomes, usage of fluoroscopy, or perioperative neurovascular injury. Given that each patient required a preoperative CT scan to identify optimal starting point and risk of significant vascular injury, the results are promising but do not yet clearly establish endoscopic transiliac surgery as a superior option for the dysmorphic pelvis.

\section{Interlaminar Approach}

The interlaminar approach has the advantage of direct insertion under endoscopic guidance [78, 82]. However, compared to the aforementioned approaches, interlaminar resection requires nerve root and thecal sac retraction which may present a particular challenge in large LDH [78]. However, both Soman et al. and Tonusu et al. demonstrate significant improvement in outcome indices following LDH resection via this method $[78,82]$. However, Tonusu et al. via the shoulder approach 
had three neurologic perioperative complications, and as such recommend that in large disc herniations with caudal extrusion access via the axillary approach should be obtained.

\section{Long-term Follow-up}

Limited long-term data is available with conflicting outcomes. Five-year data combining PELD with percutaneous lumbar foraminoplasty (PLF) demonstrates promising results with improvement in ODI and modified MacNab criteria. When combined with PLF in 134 patients, Li et al. demonstrated a 93\% 5-year patient satisfaction rate [83]. Moreover, when evaluating the outcomes of full-endoscopic interlaminar discectomy (FELD), Tu et al. also demonstrated significant 5 -year improvement in VAS, ODI, modified MacNab criteria, and 90\% 5-year good or excellent patient satisfaction [84•]. However, their patient population had an $8.3 \%$ revision surgery rate, 4.2-day mean length of stay, and $6 \%$ dural tear rate. In contrast with the above positive findings, one study with 11-year follow-up of PELD patients found a 36\% reoperation rate [85]. Additionally, re-herniation rates range from 5 to $15 \%[94,95]$. Risk factors for failure following PELD include obesity, age $>50$, surgeon inexperience, and central disc herniation [86]. Hu et al. study suggests that surgeon inexperience can be modified by preoperative planning software which demonstrated an ability to reduce mean operative and fluoroscopic time [87].

\section{Open Discectomy}

As aforementioned, over the last decade, large studies including the SPORT and Maine trials have demonstrated the efficacy of open discectomy in LDH. Approaches for discectomy vary based on herniation type (paracentral versus far lateral). While the paracentral approach has robust utility LDH, it is associated with longer incisions, increased muscle stripping, and more difficulty in far lateral discectomy [88]. Given these difficulties, the Wiltse paraspinal approach between the multifidus and longissimus muscles is a well-recognized method of discectomy in far lateral herniation [89].

Much of the current data regarding open discectomy for LDH involves infection risk as outcome data has been well published over the last several decades. Predictors of infection following microdiscectomy include absence of prophylactic antibiotic dosing and duration of surgery $>68 \mathrm{~min}$ [90]. Interestingly, one study did not find that preoperative lumbar epidural CSI increased infection risk [91]. Kotil et al. evaluated 115 patients undergoing single-level discectomy with and without closed suction drains. With MRI post-operative days 1,180 , and 365 , their data demonstrated significantly higher rates of epidural hematoma and fibrosis compared to the nonCSD group. However, there was no 12-month difference in ODI and VAS scores, or major post surgical complications
[92]. More recently, Murphy et al. evaluated the effect of microscope use during open discectomy in 23,583 patients [93]. Their findings of increased operative time and equivalent perioperative complication rates in discectomy performed with and without microscope assistance led to recommendation for continued use of the microscope during decompression per surgeon preference [93].

\section{Complications}

There are several important complications associated with discectomy for $\mathrm{LDH}$. The rate of dural tears following $\mathrm{LDH}$ ranges from 1 to $17 \%$ and is increased particularly with advanced age, obesity, and revision procedures [94]. The downstream effects of incidental durotomy include increased hospitalization costs by $\$ 4000$ and wound dehiscence odds by 2.4 times [94]. Other complications include post-operative infection (1-5\%), worsening of functional status (4\%), and nerve root injury $(0.2 \%)[92,93]$. Risk factors for recurrent herniation include pre-operative disc height index, trauma, older age, smoking, disc protrusion, disc sequestration, longer duration of sick leave, workers' compensation, greater preoperative symptom severity, and diabetes [74, 95-100]. With a substantial increase in perioperative complications in revision LDH discectomy, minimizing risk factors for recurrence are critical; however, activity restriction has not demonstrated improvement in LDH recurrence rate [101].

\section{Conclusion}

LDH is a common etiology in low back pain. In the last 3 years, significant advances have been made in our understanding in the etiology of LDH including microstructural changes, molecular pathways, and microbial load. Additionally, over this same time period, minimally invasive approaches to LDH resection have demonstrated increasingly positive outcomes. As such, this approach remains a key area of investigation in the coming years in addition to better defining the absolute indications for maximal clinical benefit in surgical treatment of LDH.

\section{Compliance with Ethical Standards}

Conflict of Interest Raj M. Amin and Nicholas S. Andrade declare that they have no conflict of interest.

Brian J. Neuman reports grants from Depuy Synthes, outside of the submitted work.

Human and Animal Rights and Informed Consent This article does not contain any studies with human or animal subjects performed by any of the authors. 


\section{References}

Papers of particular interest, published recently, have been highlighted as:

- Of importance

1. Andersson GB. Epidemiological features of chronic low-back pain. Lancet. 1999;354(9178):581-5. https://doi.org/10.1016/ S0140-6736(99)01312-4.

2. Martin BI, Deyo RA, Mirza SK, et al. Expenditures and health status among adults with back and neck problems. JAMA. 2008;299(6):656. https://doi.org/10.1001/jama.299.6.656.

3. Kadow T, Sowa G, Vo N, Kang JD. Molecular basis of intervertebral disc degeneration and herniations: what are the important translational questions? Clin Orthop Relat Res. 2015;473(6): 1903-12. https://doi.org/10.1007/s11999-014-3774-8.

4. Kepler CK, Ponnappan RK, Tannoury CA, Risbud MV, Anderson DG. The molecular basis of intervertebral disc degeneration. Spine J. 2013;13(3):318-30. https://doi.org/10.1016/j.spinee. 2012.12.003.

5. Kalb S, Martirosyan NL, Kalani MYS, Broc GG, Theodore $\mathrm{N}$. Genetics of the degenerated intervertebral disc. World Neurosurg. 2012;77(3-4):491-501. https://doi.org/10.1016/j. wneu.2011.07.014.

6. Urban JPG, Roberts S. Degeneration of the intervertebral disc. Arthritis Res Ther. 2003;5(3) https://doi.org/10.1186/ar629.

7. Brayda-Bruno M, Tibiletti M, Ito K, et al. Advances in the diagnosis of degenerated lumbar discs and their possible clinical application. Eur Spine J. 2014;23(SUPPL. 3):315-23. https://doi. org/10.1007/s00586-013-2960-9.

8. Colombier P, Clouet J, Hamel O, Lescaudron L, Guicheux J. The lumbar intervertebral disc: from embryonic development to degeneration. Jt Bone Spine. 2014;81(2):125-9. https://doi.org/10. 1016/j.jbspin.2013.07.012

9. Adams MA. Intervertebral disc tissues. In: Mechanical properties of aging soft tissues; 2015. p. 7-35. https://doi.org/10.1007/978-3319-03970-1.

10. Mayer JE, Iatridis JC, Chan D, Qureshi SA, Gottesman O, Hecht AC. Genetic polymorphisms associated with intervertebral disc degeneration. Spine J. 2013;13(3):299-317. https://doi.org/10. 1016/j.spinee.2013.01.041

11. Martirosyan NL, Patel AA, Carotenuto A, et al. Genetic alterations in intervertebral disc disease. Front Surg. 2016;3(November):115. https://doi.org/10.3389/fsurg.2016.00059.

12. Janeczko Ł, Janeczko M, Chrzanowski R, Zieliński G. The role of polymorphisms of genes encoding collagen IX and XI in lumbar disc disease. Neurol Neurochir Pol. 2014;48(1):60-2. https://doi. org/10.1016/j.pjnns.2013.04.001.

13. Hoffman H, Choi AW, Chang V, et al. Aquaporin-1 expression in herniated human lumbar intervertebral discs. Glob Spine J. 2017;7(2):133-40. https://doi.org/10.1177/2192568217694007. This new-found association between aquaporin-1 expression and radiologic findings in lumbar disc herniation provides a new avenue of investigation regarding the etiology of herniation symptoms

14. Lama P, Le Maitre CL, Dolan P, Tarlton JF, Harding IJ, Adams MA. Do intervertebral discs degenerate before they herniate, or after? Bone Jt J. 2013;95 B(8):1127-33. https://doi.org/10.1302/ 0301-620X.95B8.

15. Lotz JC, Chin JR. Intervertebral disc cell death is dependent on the magnitude and duration of spinal loading. Spine (Phila Pa 1976). 2000;25(12):1477-83. https://doi.org/10.1097/00007632200006150-00005.
16. LOTZ JC, COLLIOU OK, Chin JRJ, DUNCAN NA, Liebenberg E. Compression-induced degeneration of the intervertebral disc: an in vivo mouse model and finite-element study. Spine (Phila Pa 1976). 1998;23(23):2493-506. https://doi.org/10.1097/ 00007632-199812010-00004.

17. Paul CPL, de Graaf M, Bisschop A, et al. Static axial overloading primes lumbar caprine intervertebral discs for posterior herniation. PLoS One. 2017:1-23. The specific association of static axial overloading with posterior herniation provides a link between certain lifestyle behaviors and a particular herniation subtype. Behavioral changes may be able to reduce the incidence of posterior herniations.

18. Kobayashi S, Takeno K, Yayama T, Baba H. Pathomechanisms of sciatica in lumbar disc herniation effect of periradicular adhesive tissue on electrophysiological values by an intraoperative straight leg raising test. Spine (Phila Pa 1976). 2010;35(22):2004-14.

19. O'Donnell J, O’Donnell A. Prostaglandin E2 content in herniated lumbar disc disease.

20. Willburger R, Wittenberg R. Prostaglandin release from lumbar disc and facet joint tissue. Spine (Phila Pa 1976). 1994;19.

21. Ohtori S, Inoue G, Eguchi Y, et al. Tumor necrosis factor- $\alpha$ immunoreactive cells in nucleus pulposus in adolescent patients with lumbar disc herniation. Spine (Phila Pa 1976). 2013;38(6): 459-62. https://doi.org/10.1097/BRS.0b013e3182739cb4.

22. Kraychete DC, Rioko KS, Adriana Macado I, Bacellar O, Carvalho EM. Serum cytokine levels in patients with chronic low back pain due to herniated disc: analytical cross-sectional study. Sao Paulo Med J. 2010;128(5):259-62.

23. Liu Y, Wei J, Zhao Y, Zhang Y, Han Y, Chen B. Follistatin-like protein 1 promotes inflammatory reactions in nucleus pulposus cells by interacting with the MAPK and NF $\mathrm{K}$ B signaling pathways. Oncotarget. 2017. The discovered involvement of FSTL1 in the nucleus pulposus inflammatory pathway elaborates on upstream pathways that lead to COX-2 upregulation, and provides a possible avenue for the development of non-operative treatment of inflammation-related symptoms in patients.

24. Albert HB, Sorensen JS, Christensen BS, Manniche C. Antibiotic treatment in patients with chronic low back pain and vertebral bone edema (modic type 1 changes): a double-blind randomized clinical controlled trial of efficacy. Eur Spine J. 2013;22(4):697707. https://doi.org/10.1007/s00586-013-2675-y. Improvement of lower back pain after long-term antibiotic treatment provides strong support for a role of $P$. acnes in symptom etiology. Moreover, it suggests another possible non-operative treatment to explore: anti-anaerobe antibiotics

25. Stirling A, Worthington T, Rafiq M, Lambert PA, Elliott TSJ. Association between sciatica and Propionibacterium acnes. Lancet. 2001;357(9273):2024-5. https://doi.org/10.1016/S01406736(00)05109-6.

26. Capoor MN, Ruzicka F, Machackova T, et al. Prevalence of Propionibacterium acnes in intervertebral discs of patients undergoing lumbar microdiscectomy: a prospective cross-sectional study. PLoS One. 2016:1-12. https://doi.org/10.1371/journal. pone. 0161676 .

27. Aghazadeh J, Salehpour F, Ziaeii E, Javanshir N. Modic changes in the adjacent vertebrae due to disc material infection with Propionibacterium acnes in patients with lumbar disc herniation. Eur Spine J. 2016; https://doi.org/10.1007/s00586-016-4887-4.

28. Chen Z, Zheng Y, Yuan Y, et al. Modic changes and disc degeneration caused by inoculation of Propionibacterium acnes inside intervertebral discs of rabbits: a pilot study. Biomed Res Int. 2016;2016. https://doi.org/10.1155/2016/9612437.

29. Coscia MF, Denys GA, Wack MF. Propionibacterium acnes, coagulase-negative Staphylococcus, and the "biofilm-like" 
intervertebral disc. Spine (Phila Pa 1976). 2016;41(24):1860-5. https://doi.org/10.1097/BRS.0000000000001909.

30. Cuesta A, Del Valle ME, García-Suárez O, et al. Acid-sensing ion channels in healthy and degenerated human intervertebral disc. Connect Tissue Res. 2014;55(3):197-204. https://doi.org/10. 3109/03008207.2014.884083.

31. Kobayashi Y, Sekiguchi M, Konno S. Effect of an acid-sensing ion channels inhibitor on pain-related behavior by nucleus pulposus applied on the nerve root in rats. Spine (Phila Pa 1976). 2017. https://doi.org/10.1097/BRS.0b013e318173298b. Improved pain symptoms with blockade of ASICs solidifies the role of acidity in sciatica etiology. Furthermore, ASICS may be a novel target for non-operative treatment of pain in lumbar disc herniation.

32. Liu J, Tao H, Wang H, et al. Biological behavior of human nucleus pulposus mesenchymal stem cells in response to changes in the acidic environment during intervertebral disc degeneration. Stem Cells Dev. 2017;26(12):901-11. https://doi.org/10.1089/scd.2016.0314.

33. Vroomen P, de Krom M, Wilmink J, Kester A, Knottnerus J. Diagnostic value of history and physical examination in patients suspected of lumbosacral nerve root compression. J Neurol Neurosurg Psychiatry. 2002;72(5):630-4. https://doi.org/10. 1136/jnnp.72.5.630.

34. Vucetic N, Svennson O. Physical signs in lumbar disc hernia. Clin Orthop Relat Res. 1996.

35. Nachemson A. Disc pressure measurements. Spine (Phila Pa 1976). 1981;6(1).

36. Rainville J, Lopez E. Comparison of radicular symptoms caused by lumbar disc herniation and lumbar spinal stenosis in the elderly. Spine (Phila Pa 1976). 2013;38(15):1282-7. https://doi.org/10. 1097/BRS.0b013e31828f463e.

37. Petersen T, Laslett M, Juhl C. Clinical classification in low back pain: best-evidence diagnostic rules based on systematic reviews. BMC Musculoskelet Disord. 2017;18(1):188. https://doi.org/10. 1186/s12891-017-1549-6.

38. Krishnan V, Rajasekaran S, Aiyer SN. Clinical and radiological factors related to the presence of motor deficit in lumbar disc prolapse: a prospective analysis of 70 consecutive cases with neurological deficit. Eur Spine J. 2017. https://doi.org/10.1007/ s00586-017-5019-5. This is the first time that a risk profile with good sensitivity and specificity for cauda equina syndrome has been established for lumbar disc herniation patients. Those who meet criteria can be better monitored to prevent permanent motor deficit in these patients.

39. Kreiner DS, Hwang SW, Easa JE, et al. An evidence-based clinical guideline for the diagnosis and treatment of lumbar disc herniation with radiculopathy. Spine J. 2014;14(1):180-91. https://doi.org/ 10.1016/j.spinee.2013.08.003.

40. Kim KY, Kim YT, Lee CS, Kang JS, Kim YJ. Magnetic resonance imaging in the evaluation of the lumbar herniated intervertebral disc. Int Orthop. 1993;17(4):241-4. https://doi.org/10.1007/ BF00194188.

41. Messner A, Stelzeneder D, Trattnig S, et al. Does T2 mapping of the posterior annulus fibrosus indicate the presence of lumbar intervertebral disc herniation? A 3. 0 Tesla magnetic resonance study. Eur Spine J. 2017;26:877-83. https://doi.org/10.1007/ s00586-016-4873-x.

42. Wu W, Liang J, Ru N, et al. Microstructural changes in compressed nerve. Spine (Phila Pa 1976). 2016;41(11):661-6. https://doi.org/10.1097/BRS.0000000000001354.

43. Modic MT, Steinberg PM, Ross JS, Masaryk TJ, Carter JR. Degenerative disk disease: assessment of changes in vertebral body marrow with MR imaging. Radiology. 1988;166(1):193-9. https://doi.org/10.1148/radiology.166.1.3336678.

44. Yu LP, Qian WW, Yin GY, Ren YX, Hu ZY. MRI assessment of lumbar intervertebral disc degeneration with lumbar degenerative disease using the Pfirrmann grading systems. PLoS One. 2012;7(12):1-7. https://doi.org/10.1371/journal.pone.0048074.

45. Janssen ME, Bertrand SL, Joe C, Levine MI. Lumbar herniated disk disease: comparison of MRI, myelography, and postmyelographic CT scan with surgical findings. Orthopedics. 1994;17(2):121-7. http://europepmc.org/abstract/med/8190676

46. Notohamioridjo S, Stahl R, Braunagel M, et al. Diagnostic accuracy of contemporary multidetector computed tomography (MDCT) for the detection of lumbar disc herniation. Eur Radiol. 2016; https://doi.org/10.1007/s00330-016-4686-7.

47. Gugliotta M, Costa BR, Dabis E, et al. Surgical versus conservative treatment for lumbar disc herniation: a prospective cohort study. BMJ Open 2016:1-7. https://doi.org/10.1136/bmjopen2016-012938.

48. Wong J, Cote P, Sutton DA, et al. Clinical practice guidelines for the noninvasive management of low back pain: a systematic review by the Ontario Protocol for Traffic Injury Management (OPTIMa) Collaboration. Eur J Pain. 2017;21:201-16. https:/ doi.org/10.1002/ejp.931.

49.• Manchikanti L, Pampati V, Benyamin RM, Hirsch JA. Cost utility analysis of lumbar interlaminar epidural injections in the treatment of lumbar disc herniation, central spinal stenosis, and axial or discogenic low back pain. Pain Physician. 2017:219-228. The finding of strong QALY benefit in patients receiving intralaminar epidural injections supports the continued use of this non-operative treatment option.

50. Kepes ER, Duncalf D. Treatment of backache with spinal injections of local anesthetics, spinal and systemic steroids. A review. Pain. 1985;22(1):33-47. https://doi.org/10.1016/0304-3959(85) 90146-0.

51. Carette S, Leclaire R, Marcoux S, et al. Epidural corticosteroid injections for sciatica due to herniated nucleus pulposus. N Engl J Med. 1997;336:1634-40.

52. Ackerman WE, Ahmad M. The efficacy of lumbar epidural steroid injections in patients with lumbar disc herniations. Int Anesth Res Soc. 2007;104(5):1217-22. https://doi.org/10.1213/01.ane. 0000260307.16555.7f.

53. Altun I, Yuksel KZ. Impact of position on efficacy of caudal epidural injection for low back pain and radicular leg pain due to central spinal stenosis and lumbar disc hernia. J Korean Neurosurg Soc. 2017;60(2):205-10. Highlights benefits of performing injections in the lateral decubitus position as opposed to prone position. This provides patients with better relief at follow-up

54. Kim J, Hur JW, Ph D, et al. Surgery versus nerve blocks for lumbar disc herniation: quantitative analysis of radiological factors as a predictor for successful outcomes. J Korean Neurosurg Soc. 2016;59(5):478-84.

55. Freeman BJC, Ludbrook GL, Hall S, et al. Randomized, doubleblind, placebo-controlled, trial of transforaminal epidural etanercept for the treatment of symptomatic lumbar disc herniation. Spine (Phila Pa 1976). 2013;38(23):1986-94. https://doi.org/ 10.1097/01.brs.0000435140.61593.4c.

56. Korhonen T, Karppinen J, Malmivaara A, et al. Efficacy of infliximab for disc herniation-induced sciatica: one-year followup. Spine (Phila Pa 1976). 2004;29(19):2115-9. https://doi.org/ 10.1097/01.brs.0000141179.58778.6c.

57. Cohen SP, Wenzell D, Hurley RW, et al. A double-blind, placebocontrolled, dose response pilot study evaluating intradiscal etanercept in patients with chronic discogenic low back pain or lumbosacral radiculopathy. Anesthesiology. 2007;107(1):99-105. https://doi.org/10.1097/01.anes.0000267518.20363.0d.

58. Shin J, Lee ÃJ, Lee ÃYJ, et al. Long-term course of alternative and integrative therapy for lumbar disc herniation and risk factors for surgery. Spine (Phila Pa 1976). 2016;41(16):955-63. https:// doi.org/10.1097/BRS.0000000000001494. 
59. Zhong M, Liu JT, Jiang H, Mi W, Yu P-FCL, Xue RR. Incidence of spontaneous resorption of lumbar disc herniation: a meta-analysis. Pain Physician. 2017;6:45-52.

60. Isner-Horobeti M-E, Dufour SP, Schaeffer M, et al. High-force versus low-force lumbar traction in acute lumbar sciatica due to disc herniation: a preliminary randomized trial. J Manip Physiol Ther. 2016;39(9):645-54. https://doi.org/10.1016/j.jmpt.2016.09.006.

61. Jewell DV, Riddle DL. Interventions that increase or decrease the likelihood of a meaningful improvement in physical health in patients with sciatica. Phys Ther. 2005;85(11):1139-50.

62. Thackeray A, Fritz J, Lurie J, Zhao W, Weinstein J. Nonsurgical treatment choices by individuals with lumbar intervertebral disc herniation in the United States: associations with long-term outcomes. Am J Phys Med Rehabil. 2016:1-8. https://doi.org/10. 1097/PHM.0000000000000685.

63. Wang S, Rui Y, Tan Q, Wang C. Enhancing intervertebral disc repair and regeneration through biology: platelet-rich plasma as an alternative strategy. Arthritis Res Ther. 2013;15.

64. Basso M, Cavagnaro L, Zanirato A, et al. What is the clinical evidence on regenerative medicine in intervertebral disc degeneration ? Musculoskelet Surg. 2017; https://doi.org/10.1007/ s12306-017-0462-3.

65. Levi D, Horn S, Tyszko S, Levin J, Hecht-Leavitt C, Walko E. Intradiscal platelet-rich plasma injection for chronic discogenic low back pain: preliminary results from a prospective trial. Pain Med. 2015:pnv053. https://doi.org/10.1093/pm/pnv053.

66. Tuakli-Wosornu YA, Terry A, Boachie-Adjei K, et al. Lumbar intradiskal platelet-rich plasma (PRP) injections: a prospective, double-blind, randomized controlled study. PM R. 2016;8(1):110. https://doi.org/10.1016/j.pmrj.2015.08.010.

67. Pettine K, Suzuki R, Sand T, Murphy M. Treatment of discogenic back pain with autologous bone marrow concentrate injection with minimum two year follow-up. Int Orthop. 2016;40(1):135-40. https://doi.org/10.1007/s00264-015-2886-4.

68. Weinstein JN, Tosteson TD, Lurie JD, et al. Surgical vs nonoperative treatment for lumbar disk herniation. JAMA. 2006;296(20): 2441. https://doi.org/10.1001/jama.296.20.2441.

69. Atlas SJ, Deyo RA, Keller RB, Chapin AM, Patrick DL, Long JM, et al. The Maine lumbar spine study part II: 1-year outcomes of surgical and non-surgical management of sciatica. Spine (Phila Pa 1976). 1996;21(15):1777-86. https://doi.org/10.1097/00007632199608010-00011.

70. Osterman H, Seitsalo S, Karppinen J, Malmivaara A. Effectiveness of microdiscectomy for lumbar disc herniation. Spine (Phila Pa 1976). 2006;31(21):2409-14.

71. Ademi Z, Gloy V, Glinz D, et al. Cost-effectiveness of primarily surgical versus primarily conservative treatment of acute and subacute radiculopathies due to intervertebral disc herniation from the Swiss perspective. Swiss Med Wkly. 2016:1-14. https://doi.org/10. 4414/smw.2016.14382.

72. Oba H, Takahashi J, Tsutsumimoto T, et al. Predictors of improvement in low back pain after lumbar decompression surgery: prospective study of 140 patients. J Orthop Sci. 2017:6-11. https:// doi.org/10.1016/j.jos.2017.03.011. The identification of preoperative factors that are associated with improved discectomy outcomes may aid in selecting patients who are most likely to improve from surgical intervention.

73. Tschugg A, Lener S, Hartmann S, et al. Preoperative sport improves the outcome of lumbar disc surgery: a prospective monocentric cohort study. Neurosurg Rev. 2017; https://doi.org/ 10.1007/s10143-017-0811-6.

74. Wilson CA, Roffey DM, Chow D, Alkherayf F, Wai EK. A systematic review of preoperative predictors for postoperative clinical outcomes following lumbar discectomy. Spine J. 2016;16(11): 1413-22. https://doi.org/10.1016/j.spinee.2016.08.003.
75. Hsu HT, Chang SJ, Yang SS, Chai CL. Learning curve of fullendoscopic lumbar discectomy. Eur Spine J. 2013;22(4):727-33. https://doi.org/10.1007/s00586-012-2540-4.

76. Cahill KS, Levi AD, Cummock MD, Liao W, Wang MY. A comparison of acute hospital charges after tubular versus open microdiskectomy. World Neurosurg. 2013;80(1-2):208-12. https://doi.org/10.1016/j.wneu.2012.08.015.

77. Bai J, Zhang W, Wang Y, et al. Application of transiliac approach to intervertebral endoscopic discectomy in L5/S1 intervertebral disc herniation. Eur J Med Res. 2017;22(14):4-13. https://doi. org/10.1186/s40001-017-0254-0.

78. Tonosu J, Oshima Y, Shiboi R, Hayashi A, Takano Y, Koga H. Consideration of proper operative route for interlaminar approach for percutaneous endoscopic lumbar discectomy. J Spine Surg. 2016;2(4):281-8. 10.21037/jss.2016.11.05.

79. Phan K, Xu J, Schultz K, et al. Full-endoscopic versus microendoscopic and open discectomy: a systematic review and metaanalysis of outcomes and complications. Clin Neurol Neurosurg. 2017;154:1-12. https://doi.org/10.1016/j.clineuro.2017.01.003.

80. Overdevest G, Peul WC, Brand R, et al. Tubular discectomy versus conventional microdiscectomy for the treatment of lumbar disc herniation: Two year results of a double-blinded randomised trial. Acta Neurochir. 2010;152(4):747. https://doi.org/10.1136/jnnp2016-315306.

81. Choi K, Lee DC, Shim H, Shin S, Park C. A strategy of percutaneous endoscopic lumbar discectomy for migrated disc herniation. World Neurosurg. 2017;99:259-66. https://doi.org/10.1016/j. wneu.2016.12.052.

82. Soman SM, Modi JV, Chokshi J. Feasibility of endoscopic discectomy by inter laminar approach at a high volume tertiary public hospital in a developing country. J Spine Surg. 2017;3(1): 38-43. https://doi.org/10.21037/jss.2017.03.10.

83. Li Z, Hou S, Shang W, Song K, Zhao H. Modified percutaneous lumbar foraminoplasty and percutaneous endoscopic lumbar discectomy: instrument design, technique notes, and 5 years follow-up. Pain Physician. 2017;20:85-98.

84. Tu Z, Li YW, Wang B, et al. Clinical outcome of full-endoscopic interlaminar discectomy for single-level lumbar disc herniation: a minimum of 5-year follow-up. Pain Physician. 2017;(3):425-430. Demonstrates good outcomes for interlaminar discectomy conducted entirely endoscopically. There is high potential for successfully minimally invasive surgery for single-level disc herniation.

85. Eun SS, Lee SH, Sabal LA. Long-term follow-up results of percutaneous endoscopic lumbar discectomy. Pain Physician. 2016;19:1161-6.

86. Yao Y, Liu H, Zhang H, et al. Risk factors for recurrent herniation after percutaneous endoscopic lumbar discectomy. World Neurosurg. 2017;100:1-6. https://doi.org/10.1016/j.wneu.2016. 12.089 .

87. Hu Z, Li X, Cui J, et al. Significance of preoperative planning software for puncture and channel establishment in percutaneous endoscopic lumbar DISCECTOMY: a study of 40 cases. Int J Surg. 2017;41:97-103. https://doi.org/10.1016/j.ijsu.2017.03.059.

88. Choi K, Kim J, Lee C. Outcome of decompression alone for foraminal/extraforaminal entrapment of L5 nerve root through Wiltse paraspinal approach. Clin Spine Surg. 2016:1-7.

89. Wiltse L, Spencer C. New uses and refinements of the paraspinal approach to the lumbar spine. Spine (Phila Pa 1976). 1988;13(6).

90. Habiba S, Nygaard ØР, Brox JI, Hellum C, Austevoll IM, Solberg TK. Risk factors for surgical site infections among 1,772 patients operated on for lumbar disc herniation: a multicentre observational registry-based study. Spine (Phila Pa 1976). 2017; https://doi.org/ 10.1007/s00701-017-3184-2.

91. Seavey JG, Balazs GC, Steelman T, Gwinn DE, Wagner SC. The effect of preoperative lumbar epidural corticosteroid injection on 
post-operative infection rate in patients undergoing single-level lumbar decompression. Spine J. 2017; https://doi.org/10.1016/j. spinee.2017.04.003.

92. Kotil K. Closed drainage versus non-drainage for single-level lumbar disc surgery: relationship between epidural hematoma and fibrosis. Asian Spine J. 2016;10(6):1072-8.

93. Murphy ME, Hakim JS, Kerezoudis P, et al. Micro vs. macrodiscectomy: does use of the microscope reduce complication rates? Clin Neurol Neurosurg. 2017;152:28-33. https://doi. org/10.1016/j.clineuro.2016.11.010.

94. Puvanesarajah V, Hassanzadeh $\mathrm{H}$. The true cost of a dural tear. Spine (Phila Pa 1976). 2017;42(10):770-6. https://doi.org/10. 1097/BRS.0000000000001895.

95. Shin B-J. Risk factors for recurrent lumbar disc herniations. Asian Spine J. 2014;8(2).

96. Huang W, Han Z, Liu J, Yu L, Yu X. Risk factors for recurrent lumbar disc herniation. Medicine (Baltimore). 2016;95(2):1-10. https://doi.org/10.1097/MD.0000000000002378.
97. Cinotti G, Roysam GS, Eisenstein SM, Postacchini F. Ipsilateral recurrent lumbar disc herniation. A prospective, controlled study. J Bone Jt Surg. 1993;80-B:825-32.

98. Kim K, Park S, Kim Y. Disc height and segmental motion as risk factors for recurrent lumbar disc herniation. Spine (Phila Pa 1976). 2009;34(24):2674-8.

99. Belykh E, Krutko AV, Baykov ES, Giers MB, Preul MC, Byvaltsev VA. Preoperative estimation of disc herniation recurrence after microdiscectomy: predictive value of a multivariate model based on radiographic parameters. Spine J. 2017;17(3): 390-400. https://doi.org/10.1016/j.spinee.2016.10.011.

100. Hegarty D, Shorten G. Multivariate prognostic modeling of persistent pain following lumbar discectomy. Pain Physician. 2012;15(5):421.

101. Carragee EJ, Han MY, Yang B, Kim DH, Kraemer H, Billys J. Activity restrictions after posterior lumbar discectomy: a prospective study of outcomes in 152 cases with no postoperative restrictions. Spine (Phila Pa 1976). 1999;24(22):2346-51. 